\title{
Causes of traffic congestion in urban areas. Case of Poland
}

\author{
Aleksandra Koźlak $^{1, *}$, and Dagmara Wach $^{1}$ \\ ${ }^{1}$ University of Gdansk, Faculty of Economics, 119/121 Armii Krajowej St., 81-824 Sopot, Poland
}

\begin{abstract}
The dynamic development of urban areas poses increasingly more challenges for the provision of transport services for the population. The concentration of the economic potential and population in the metropolitan areas results in the occurrence of large transport needs, and when these needs are met at the same time, the phenomenon of congestion occurs. The purpose of the article is to research the relationship between various factors contributing to congestion in urban traffic and the level of congestion in Polish cities. The authors have used statistical methods such as correlation and regression analysis. The research has shown that the most statistically significant relationships have occurred in the case of the number of business entities and the number of passenger cars. It can be concluded that the demand side factors are more important in Polish cities than the supply side factors or perhaps the current transport policy is ineffective. When effectively applied, transport policy instruments can play a special role. These instruments can contribute to reducing congestion in various ways, i.e. by implementing various sub-objectives, which include reducing the need to travel, reducing the use of passenger cars, improving the functioning of public transport and use of the infrastructure. The results of this study can be useful for transport policy makers at central, regional and local levels.
\end{abstract}

\section{Introduction}

The concentration of the economic potential and population in the metropolitan areas results in the occurrence of very large transport needs in a spatially limited area, and when these needs are met at the same time, the congestion occurs. This applies to congestion in respect of both the road network and the vehicles. Significant disproportions between the transport needs and the possibilities of their meeting at the desired level of quality can be seen also in Polish cities.

Traffic congestion has become a serious problem in many cities around the world and it is a challenge that is not easy to manage. More than half a century ago Reynolds wrote that "congestion has become an almost universal phenomenon in the cities of the advanced world and few cities have escaped the problem and even fewer, if any, have as yet solved it"[1]. Since then, congestion has become a quite common and a major problem for human mobility and it has only increased in size, scope and complexity. Traffic congestion has negative

\footnotetext{
*Corresponding author: a.kozlak@ug.edu.pl
} 
impact on economic, social, and environment development [2]. From the economic point of view, congestion generates an increase in the costs of transport. The costs of congestion include costs of delays, growing operating costs of vehicles (mainly fuel), emissions of pollutants, as well as costs of stress resulting from disturbances in the vehicle traffic.

The main objective of this article is to research the relationship between various factors contributing to congestion in urban traffic by analysing the causes of congestion in Polish cities, and thus, to contribute to a better understanding of the urban congestion issues.

The first part of the article discusses the problem of transport congestion in cities, its types and main causes pointed in the literature. The subsequent part of the paper contains the description of the research method and results of correlation and regression analysis of factors contributing to congestion in Polish cities. The knowledge of causes of traffic congestion on road networks and evaluation of its level are important for traffic management and control. At the end, the results of the research and possible policy instruments useful to reduce transport congestion in Poland are discussed.

\section{Defining congestion and characterising its causes - literature review}

In general, the concept of congestion may be related to a situation in which a good is used or consumed collectively by a larger number of buyers and this good cannot be provided in the form of separate units. The condition for congestion to occur is that a larger number of users or consumers of a given good will cause negative effects, mainly consisting in hindering others from having access to these resources. The situation described above is common in transport where congestion occurs on a large scale, causes lots of nuisance, and its costs are high. Congestion occurs when traffic on the road is delayed due to the presence of other vehicles. Along with an increase in demand exceeding the capacity of an infrastructure facility, the costs of users grow and the quality of using the facility deteriorates [3].

Transport congestion is defined as mutual obstruction of traffic by vehicles due to the existing interrelation between the speed of moving vehicles and the volume of flows in the conditions of depletion of the infrastructure capacity. In other words, congestion is associated with such a level of vehicle traffic that exceeds the capacity of a given road which results in a decrease in the speed of moving vehicles or total prevention of free movement $[4,5]$. Congestion is a result of an imbalance of the travel demand and the transport system supply. The demand results from the concentration of travel in space and time. The supply is constrained by the historical shape of the infrastructure, the level of investment, transport management and operating practices [6].

The European Conference of Ministers of Transport (ECMT) has stated that there is no single definition for traffic congestion and it can be determined in different ways [7]. The term congestion can be applied fairly narrowly to near-jam conditions or more broadly to describe any loss of speed due to weight of traffic [8]. Congestion can be analysed as a physically measurable phenomenon or as perceived by users of the road network, residents and others, and the level of congestion in these approaches will be different. For policy measures, subjective perceived congestion may be as important as the more objective evidence in driving the need [9].

Congestion in the urban transport network is common not only in large agglomerations, but also in medium-sized cities in all countries that are characterized by a high level of socioeconomic development. In cities, we are dealing with a large concentration of transport needs in time and space that occur with a specific periodicity. With heavy traffic, a dense road network is conducive to congestion at crossroads, and from there, on a chain reaction basis, it moves to sections of streets between crossroads and then to neighbouring crossroads. Different types of transport congestion are distinguished in the network depending on the 
degree of its escalation. One of the frequently used categorizations of congestion is Vickrey's differentiation, in which successive phases of increasing disruptions in the vehicle traffic are taken into account $[10,11]$ :

- a single interaction between two vehicles, resulting in a reduction in the speed of one of them in relation to the speed at which it could move if the other vehicle was not there;

- multiple interactions occur between many vehicles with high traffic volumes, where although the capacity is not reached, an additional vehicle causes more impedance to each other vehicles and it leads to a reduction in their speed and longer journey times;

- bottleneck congestion occurs on sections of the road network the capacity of which is smaller than on adjacent sections, and the number of vehicles attempting to cross this section is larger than its capacity;

- triggerneck congestion develops when bottlenecks start to hinder traffic on other sections of the network, e.g. those crossing a jammed street;

- network and control congestion occur where traffic controls programmed for peak-hour traffic inevitably delay off-peak hour traffic.

The increasing level of motorisation and the increasing number of vehicles on streets have resulted in defining an additional type of congestion called the gridlock, which means traffic stopping in the whole street network in a certain area. Such a situation usually occurs in the very centres of cities.

A congestion as temporary situation in which the demand for road space exceeds the capacity is a simplistic view of this phenomenon, as the nature of the gap between demand and supply can be of very different character. Congestion can be recurrent (regular, occurring on a daily, weekly or annual cycle) or non-recurrent and it can be located across a network or at some points. The main difference among them is related to the predictability of the occurrence. Recurrent congestion is predictable and exists when the traffic volume on a road exceeds its capacity at a particular location during repeated time of day. Non-recurrent congestion is instead caused by random or unpredictable events that temporarily increase demand or reduce capacity of infrastructure. It can be generated by traffic accidents, disabled vehicles, road construction or maintenance, adverse weather conditions or demand fluctuation (for example during holidays) [12].

A recurrent congestion is a complex phenomenon, influenced by socioeconomic, technical, and human factors. The importance of each factor varies from one city to another and across time. The level of congestion in any city depends on the range of supply and demand factors. On the supply side, the principal factor is the size and capacity of the road network. Insufficient capacity of the road network can be caused by lack of investments in the transport infrastructure or lack of possibilities to expand it. Other supply side factors include the level of investment in the development of public transport as alternative means of travel. On the demand side, the principal drivers are the amount of travel undertaken by the population, the percentage of the workforce that commutes by car and the population density [13].

The report of the ECMT on managing urban traffic congestion indicates three broad categories of causal factors that impact road traffic congestion [7]:

- micro-level factors, e.g. those that relate to traffic on the roadway - congestion "triggers",

- macro-level factors that relate to demand for road use and exogenous factors that relate to patterns and volumes of trip-making - congestion "drivers",

_ "random" variables such as weather and visibility etc.

Congestion "triggers" immediately give rise to traffic congestion at the micro level. They result from too many vehicles for the design of a given roadway, dynamic changes in roadway capacity caused by lane-switching and car-following behaviour, etc. 
Congestion "drivers" operate at the macro level and contribute to the incidence of congestion and its severity. They are linked to factors like land-use patterns, employment patterns, car ownership trends, infrastructure investment, regional economic dynamics, etc. One of the major drivers of congestion and delays is the concentration of economic activity in and around major cities. Economic growth and social development increase mobility in cities and promote the use of private cars. Growth in the size of the city also generates a greater amount of traffic. The activity patterns which are determined by demographic, social and economic factors have an impact on the travel behaviour of individuals, households and enterprises (e.g. time/schedule, route, mode choice). Travel behaviour gives rise to a level of the travel demand which is spread out in time and space. The travel demand leads to a general level of the traffic flow and to specific mixes of vehicles and drivers on roadway network [7].

\section{Methodology of research}

Focusing on the main objective of this article, an appropriate methodology needs to be applied. Various congestion factors in cities having been reviewed, a set of indicators was selected to examine whether they have a significant impact on the congestion level in Polish large cities. The subject of the research are factors at the macro level. They were divided into two groups: demand and supply factors. The operationalization of congestion factors mentioned in the literature is presented in Table 1.

Table 1. Operationalization of drivers influencing the level of congestion.

\begin{tabular}{|c|c|}
\hline Driver & Indicator \\
\hline \multicolumn{2}{|r|}{ Demand side factors } \\
\hline 1. Population & Density of population (number of inhabitants per $1 \mathrm{~km}^{2}$ ) \\
\hline 2. Employment pattern & Employment rate (number of employees per 1,000 inhabitants) \\
\hline 3. Income levels & Average monthly gross wage (PLN) \\
\hline 4. Economic activity & Business entities in REGON register (number of entities) \\
\hline 5. Passenger cars & Passengers cars (number of vehicles) \\
\hline \multicolumn{2}{|r|}{ Supply side factors } \\
\hline 6. Land-use pattern & City area $\left(\mathrm{km}^{2}\right)$ \\
\hline 7. Infrastructure investments & $\begin{array}{l}\text { Expenditures on transport and communication per } 1 \text { inhabitant } \\
\text { in } 2010-2016 \text { (PLN) }\end{array}$ \\
\hline 8. Public transport & $\begin{array}{l}\text { Density of public transport routes - buses/trams/trolleys } \\
\left(\mathrm{km} \text { per } 1 \mathrm{~km}^{2}\right)\end{array}$ \\
\hline 9. Cycling infrastructure & Density of cycle paths (km per 10,000 inhabitants) \\
\hline
\end{tabular}

The linear regression analysis using the least squares method was used to examine the relationship between factors contributing to the congestion in urban traffic and the level of congestion in Polish cities. In order to eliminate the least significant variables for this linear regression model, a stepwise backward regression method was used [14, 15]. The baseline model was the model containing all explanatory variables and significance level for Fisher's F. In the first step, F-statistics and the corresponding significance levels p-value for each explanatory variable were calculated and then, the variable, for which the p-value exceeded $\alpha=0,05$ the most was removed,. The procedure was repeated until no variables could be removed from the model. 


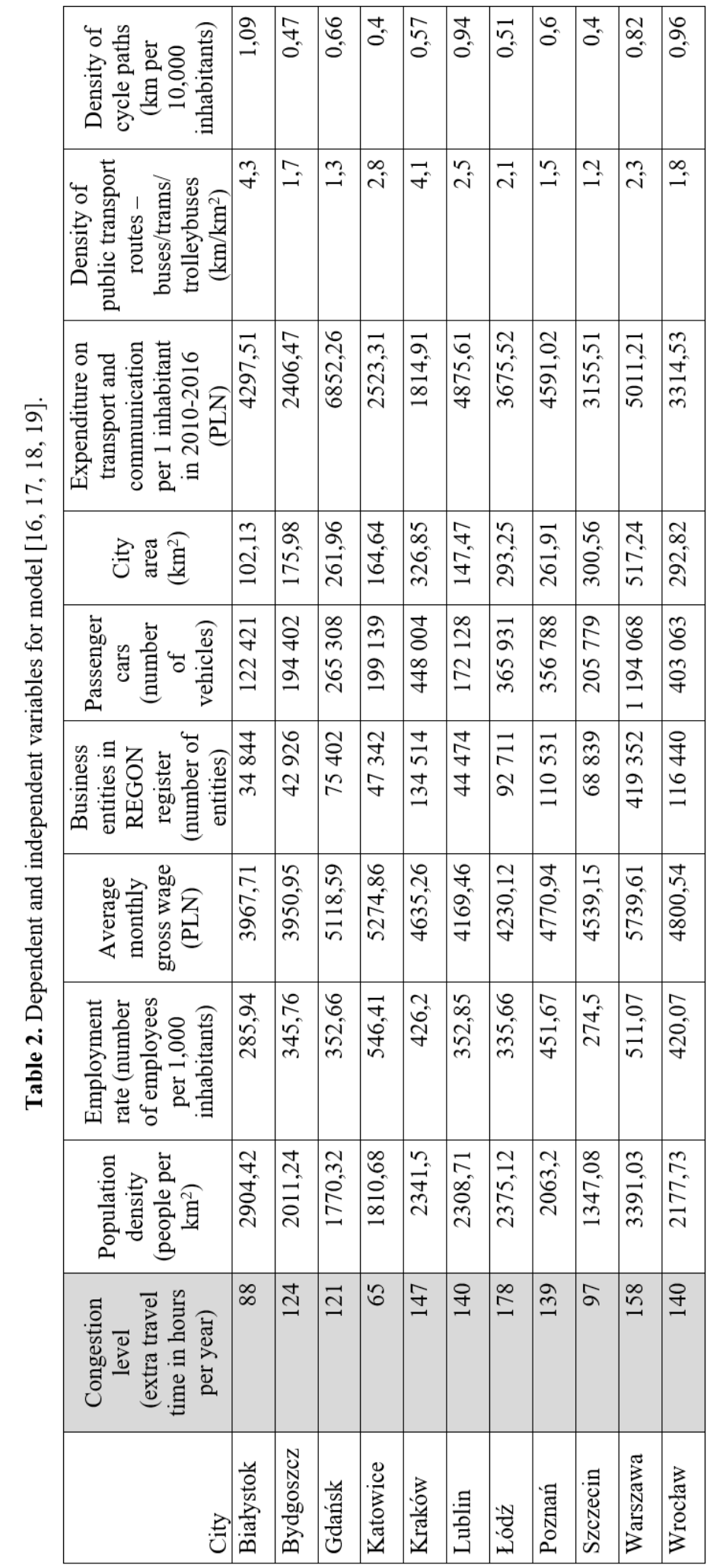


The research covered eleven Polish voivodship cities (Białystok, Bydgoszcz, Gdańsk, Katowice, Kraków, Lublin, Łódź, Poznań, Szczecin, Warsaw and Wrocław), for which information on delays on the transport network is recorded by TomTom, a satellite navigation manufacturer. The figures for the analysis concern the year 2016 and they were obtained from the Central Statistical Office [14], the Local Government Analysis System [15], the Economic Chamber of Urban Transport [16] and from the TomTom website [17].

The dependent variable was the level of congestion, determined as an increase in the travel time during the year, compared to a situation where the traffic runs smoothly (number of hours). The independent variables are the demand and supply factors affecting the level of congestion presented in Table 2.

\section{Research results}

An initial analysis of the data showed that at the significance level of 0.05 , the factors commonly considered as the causes of congestion did not show any strong relationships with the level of congestion in Polish large cities. The p-value for all factors was greater than 0.05 . After analysing the backward stepwise regression $[14,15]$, the least relevant factors for this model were eliminated, i.e. population density and density of public transport routes, because of collinearity with other factors. This resulted in a set of seven variables (Table 3.), which in more than $99.78 \%$ explain the level of congestion in Polish cities. The Pearson correlation coefficient for this model was 0.99 . This means that the level of congestion is strongly dependent on the interactions occurring between the other factors.

Table 3. The results of backward stepwise regression

\begin{tabular}{|l|c|c|c|c|c|c|}
\hline \multicolumn{1}{|c|}{ Indicator } & $\mathrm{B}^{* *}$ & $\begin{array}{c}\text { Standard } \\
\text { error of } \\
\mathrm{B}^{* *}\end{array}$ & $\mathrm{~b}$ & $\begin{array}{c}\text { Standard } \\
\text { error of } \mathrm{b}\end{array}$ & $\mathrm{t}(1)$ & $\mathrm{p}^{*}$ \\
\hline Employment rate & 0.9274 & 0.0908 & 0.3466 & 0.0340 & 10.2093 & 0.0020 \\
\hline Average monthly gross wage & -1.5520 & 0.0967 & -0.0899 & 0.0056 & -16.0515 & 0.0005 \\
\hline Business entities according to REGON & -5.4635 & 0.5473 & -0.0016 & 0.0002 & -9.9831 & 0.0021 \\
\hline Passenger cars & 4.7608 & 0.5509 & 0.0005 & 0.0001 & 8.6413 & 0.0033 \\
\hline City area & 1.7915 & 0.1176 & 0.5189 & 0.0341 & 15.2311 & 0.0006 \\
\hline $\begin{array}{l}\text { Expenditures on transport } \\
\text { and communication per 1 inhabitant }\end{array}$ & 0.4409 & 0.0618 & 0.0100 & 0.0014 & 7.1330 & 0.0057 \\
\hline $\begin{array}{l}\text { Density of cycle paths per 10 thousand } \\
\text { inhabitants }\end{array}$ & 0.4262 & 0.0773 & 19.7222 & 3.5765 & 5.5144 & 0.0117 \\
\hline Constant term & & & 167.6832 & 18.7264 & 8.9544 & 0.0029 \\
\hline
\end{tabular}

$* \alpha=0,05$

** values after standardization

The analysis also shows that the number of businesses operating in a given city and the number of registered passenger cars had the greatest impact on the level of congestion in Polish cities. The smallest impact on congestion was observed in the number of cycle paths per 10,000 inhabitants and the expenditure on transport and communication per 1 inhabitant. On the other hand, the residual analysis has shown that two cities: Katowice and Warsaw contributed the most to the final form of the regression equation. 


\section{Discussion and conclusions}

The conducted research has shown that the level of congestion in large Polish cities is influenced by similar factors, as is the case in other countries, where similar studies were carried out. However, the severity of the impact of individual factors or even groups of factors is different. Considering the division into demand and supply factors, it can be noted that it is the demand factors resulting from the level of economic and social activity and the number of passenger cars that have more significance in Poland. In metropolises with the largest concentration of people and businesses, there is an accumulation of the transport needs which to a large extent are met by the road transport. This applies both to the transport of people and freight. The cities with the greatest problems with congestion are Łódź, Warsaw, Kraków and Lublin.

The motorisation rate in Poland is high - in 2016 it was 564 passenger cars per 1000 inhabitants, while in individual cities it ranged from 412 in Lublin to 680 in Warsaw [14]. The average for EU-28 was just over 500 cars per 1000 inhabitants. Inhabitants of Polish cities commonly use passenger cars in their daily trips. According to traffic surveys conducted in different Polish cities, approximately $30-45 \%$ of displacements are made by passenger cars. Using a passenger car as the main means of transport is also favoured by suburbanisation and uncontrolled urban sprawl. The development of suburban areas is also connected with longer distances to be covered, and thus with increasing mobility. For this reason, congestion occurs not only in city centres, but also on access roads to the central parts of cities.

The lowest impact on congestion was observed in the case of the level of bicycle infrastructure development and expenditure on the development of the infrastructure and public transport, while the density of public transport routes proved to be irrelevant. These are supply-related factors that involve both the development of the road infrastructure and support of alternative forms of transport with respect to passenger cars. This may be surprising, as in principle, a better offer of the public transport should encourage people to use it or encourage them to choose a bicycle where there is a well-developed bicycle infrastructure. The results of the survey may indicate that the transport policy of Polish cities is ineffective, and the instruments used are not effective in reducing congestion in specific conditions.

The transport policy instruments cover both conventional modes of impact, which include infrastructure development, traffic management, and fee systems, as well as new ones related to the use of ICT or influencing changes in the transport behaviour of the population. In urban areas with significant road infrastructure density, solving transport problems by expanding the infrastructure is not very effective as each capacity reserve obtained in this way is utilized very rapidly.

In Polish cities, bottlenecks are a significant and still unresolved problem, despite large expenditures for the development and modernization of the road transport infrastructure. For this reason, in some cases, the construction of a new road infrastructure or equipping it with new engineering facilities may prove to be necessary. However, it is paramount to look for other solutions that would allow better use of the existing infrastructure. Today, there are large possibilities for increasing the capacity through the use of technologically advanced traffic control systems, however, they have been implemented in Poland only recently and 
relatively slowly. Traffic Management Systems (TMS) are considered one of the most effective tools to control congestion in urban areas.

Knowledge about the significance of specific factors affecting the level of congestion, and particularly the greater importance of the demand than supply factors, should encourage policy makers to more intensively use spatial and demand management instruments to influence transport behaviour of urban residents and reduce the mobility needs. Instruments related to spatial development to the largest extent contribute to reducing the overall need to travel. The spatial development planning must take into consideration the need to ensure accessibility of transport to places of human activity (work, school, culture, entertainment, etc.). Good space planning can make it easier to mover on foot, by bicycle or use the public transport to reach most of various destinations.

Transport demand management is a demand-oriented approach to the passenger and freight transport, which consists in attempts to influence people's decisions still before the journey, and the impact is directed at individual transport needs. Usually, the "soft" means of influencing transport users are used, based on information, communication, organization, coordination and promotion. However, price instruments are the most effective way to reduce the use of the cars. The demand management is complemented by traditional infrastructurebased solutions by influencing the mobility behaviour, drawing people's attention to more reasonable mobility.

It is worth emphasizing that traffic management focusing on the micro level has limited impact if congestion management strategies do not also take into account causal and contributing factors on the macroscopic scale and outside of the transport environment [7].

\section{References}

1. D.J. Reynolds, J Ind Econ 11, 2, 132-144 (1963)

2. W.R. Black, Social and economic factors in transportation, Transportation in the new millennium: state of the art and future directions, Perspectives from Transportation Research Board Standing Committees, Available at: http://onlinepubs.trb.org/onlinepubs/millennium/00100.pdf

3. H. Link, J.S. Dodgson, M. Maibach, M. Herry, The costs of road infrastructure and congestion in Europe (Physica-Verlag, Heidelberg 1999)

4. G. Weisbrod, D. Vary, G. Treyz, Transp Res Rec 1839, 1, 98-106 (2003)

5. P.B. Goodwin, The economic costs of road traffic congestion, Discussion Paper Rail Freight Group (Transport Studies Unit, University College London 2004), Available at: http://discovery.ucl.ac.uk/1259/1/2004_25.pdf

6. J.C. Falcocchio, H.S. Levinson, Road traffic congestion: a concise guide (Springer International Publishing AG, 2015)

7. Managing urban traffic congestion (Transport Research Centre, European Conference of Ministers of Transport, 2007), Available at: https://www.itfoecd.org/sites/default/files/docs/07congestion.pdf

8. Perceptions of congestion: report on qualitative research findings (Great Britain, Department for Transport, Local Government and the Regions, 2001) 
9. L. Mussone, S. Grant-Muller, J. Laird, Case Stud. Transp. Policy 3, 44-54 (2015)

10. W. Vickrey, Am. Econ. Rev., 59, 2, 251-260 (1969)

11. K.J. Burton, Transport economics, Elgar, ed. 3rd (2010)

12. Ferrara, S. Sacone, S. Siri, Freeway traffic modelling and control (Springer International Publishing, 2018)

13. The future economic and environmental costs of gridlock in 2030. An assessment of the direct and indirect economic and environmental costs of idling in road traffic congestion to households in the UK, France, Germany and the USA (Centre for Economics and Business Research 2014), Available at:

https://www.ibtta.org/sites/default/files/documents/MAF/Costs-of-Congestion-INRIXCebr-Report\%20(3).pdf

14. A.D. Aczel, Statystyka w zarządzaniu (PWN, Warszawa, 2000)

15. R.I. Jennrich, P.F. Sampson, Technometrics 10, 1, 63-72 (1968)

16. Główny Urząd Statystyczny, Available at: http://stat.gov.pl/

17. System Analiz Samorządowych, Available at: http://systemanaliz.pl/

18. Komunikacja miejska w liczbach (Izba Gospodarcza Komunikacji Miejskiej, 2016)

19. TomTom Traffic Index, Available at: https://www.tomtom.com/en_gb/trafficindex/ 